\title{
Structural analysis and numerical simulation of a new energy saving quartz melting furnace
}

\author{
Z. ZHAO ${ }^{1}$, S.G. ZHU ${ }^{1}$ \& J.W. ZHU ${ }^{1} \&$ Y.F. ZHANG ${ }^{2}$ \& H.L. ZHANG ${ }^{2}$ \\ ${ }^{1}$ Lianyungang Research Institute, Nanjing University of Science and Technology, China \\ ${ }^{2}$ School of Energy and Power Engineering, Nanjing University of Science and Technology, China
}

KEY WORDS: quartz, melting, insulation, energy saving, heating

ABSTRACT:A new type quartz melting furnace to avoid shortages of traditional quartz furnace such as high cost of graphite electrode, low production efficiency, high quartz melting furnace energy consumption is tested and simulated in this paper. Simulation is done as well as the experiment to test distribution of every sensor points. On the basis of comprehension of both results, a design 3-stage continuous furnace is given and then simulated. According to the later simulation, the energy consumption of new type furnace is $0.868 \mathrm{kWh} / \mathrm{kg}$, which means $51 \%$ energy saving comparing with the traditional type's consumption of $1.786 \mathrm{kWh} / \mathrm{kg}$.

\section{INTRODUCTION}

The quality of quartz melt is directly related to quality of subsequent products [1]. At present, the problem of high energy consumption and low purity of quartz melting furnace is obvious, power consumption accounted for $60 \%$ of total cost. In recent years, Shen Fasong [2] stuck on the outer surface with the heating wire, heating resistance wire and quartz wool insulation layer together ensure the insulation effect of tank, so that the heat preservation time in the process of acid cleaning is ensured. Zhengyou [3] limited company reform the heat insulation layer, the quartz sand was replaced by carbon graphite felt and graphite felt, this material is better than that of porous particles.

Therefore, new fused quartz furnace technology research breakthrough can reduce power consumption, reduce operation and maintenance costs, it will on the fused silica industrial have great benefits. Based on this purpose, this paper studies the key technologies of energy saving in the new generation of quartz melting furnace. 


\section{EXPERIMENTS AND NUMERICAL SIMULATIONS}

\section{Experimental platform construction}

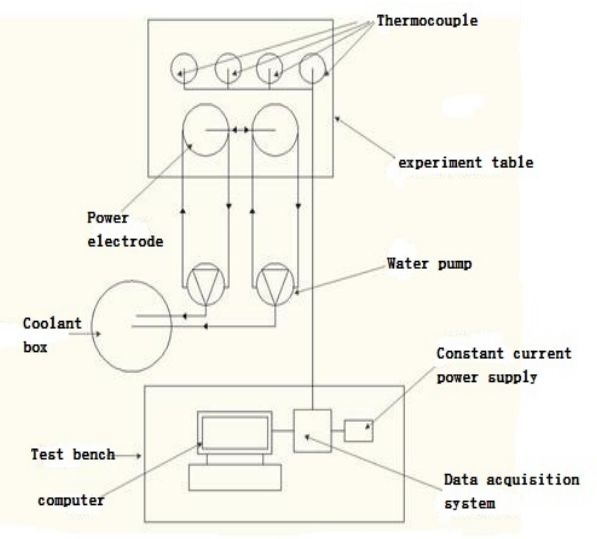

Figure 1 experiment system

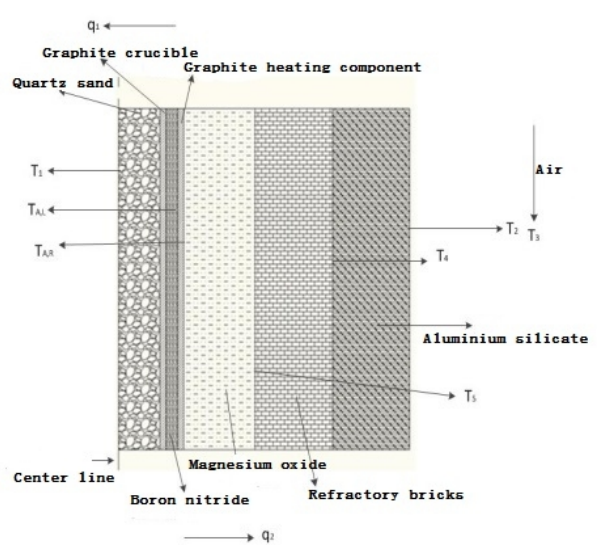

Figure 2 insulation layer distribution

The quartz melting furnace is designed in this paper,design and calculate along the axis of the right half plane, the central axis is treated as heat insulation.

\section{Experimental part}

The quartz melting test platform is built and the experiment is carried out. Obtain temperature variation of the graphite heating component.

\section{Numerical simulation}

Build model and do grid division, the grid is mainly composed of hexahedral mesh rules, using Fluent processing software ICEM CFD to draw the hexahedral mesh.

The main purpose of this simulation is to compare the simulation results with the experimental values, verify the rationality of the whole numerical simulation, In order to optimize the quartz melting furnace, provide the basis for the simulation of high temperature section. The simulation process, the temperature of the graphite heating element from the room temperature rise to 1300 , the temperature of the unit is Kelvin

\section{Comparison between simulation and experiment}

The experimental temperature of the heating process is shown in Figure 3. The total variation trend of the simulation value is in agreement with the experimental values, but there is still a certain deviation.

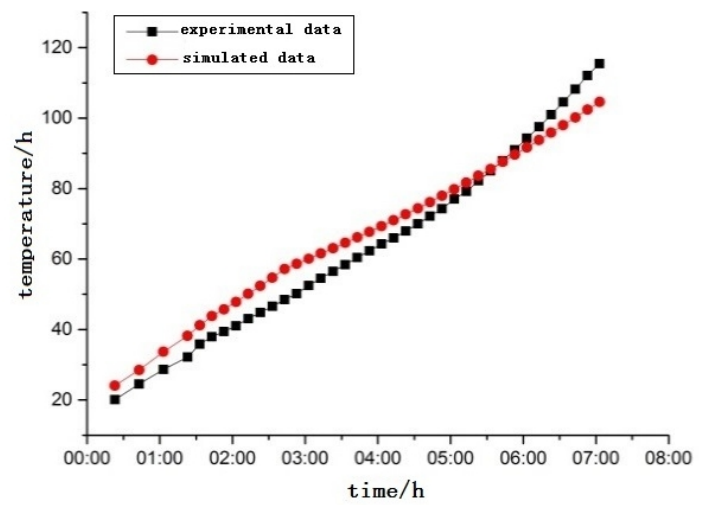

(a) Heating power $8.5 \mathrm{kw}$ 


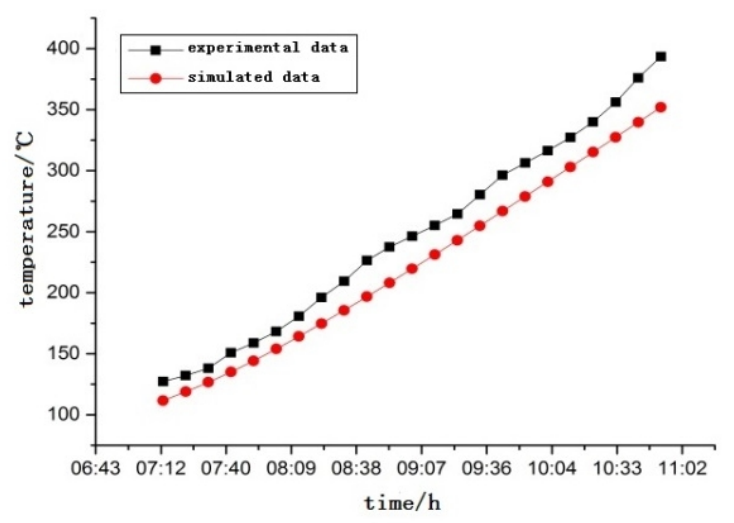

(b) Heating power 13kw

Figure 3 Temperature of $\mathrm{MgO}$ layer

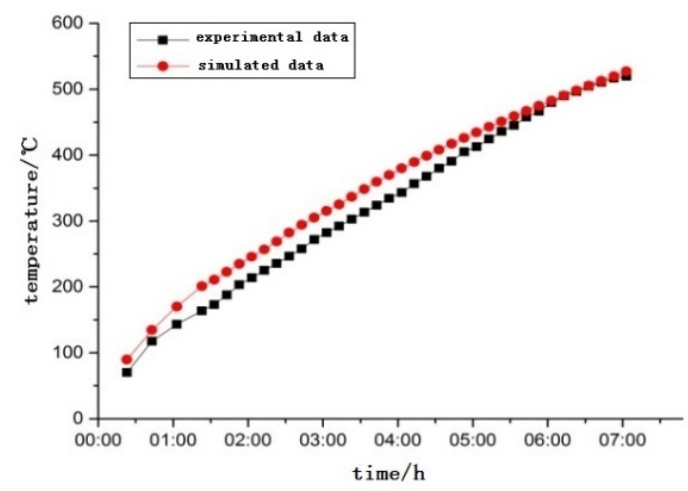

(a) Heating power $8.5 \mathrm{kw}$

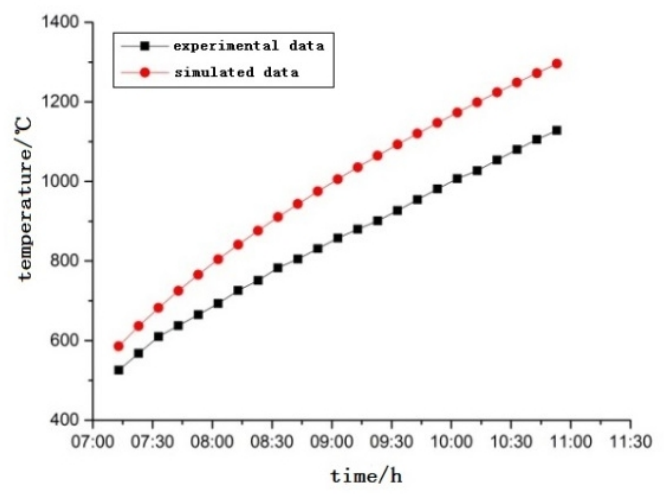

(b) Heating power 13kw

Figure 4 Temperature of graphite heating element

From Figure 3, the experimental value of the $\mathrm{MgO}$ layer is less than the simulation value at the start stage, and it is larger than the simulation value at $6 \mathrm{~h}$, and it continues to maintain this trend. From Figure 4, the temperature of the graphite heating element is always less than the simulation value.

Here's two reasonable causes:

(1) The heat transfer between the particles includes heat conduction, convection heat transfer and radiation heat transfer. The air flow in the furnace is not obvious, so the convection heat transfer can be neglected. In low temperature area, the effect of radiation heat transfer is poor, heat conduction is dominant. Because of the contact resistance between particles, the experimental value of thermal resistance is greater than that of simulation. The experimental heat transfer effect 
is worse than the simulated value. As shown in Figure 3, at the low temperature section, the actual temperature in the experimental area is lower than the simulated temperature in the low temperature region. With temperature rise, radiant heat transfer intensity is increasing, heat transfer effect is getting better and better. So at this temperature, the thermal conductivity of the simulation is less than the actual value, heat transfer effect is also different from the experimental value. As shown in Figure 4, at high temperature, the actual temperature in the experimental region is higher than that of the low temperature zone, it will maintain this state.

(2) Magnesium oxide layer to enhance heat transfer, more heat export to an external heat source, heat supply graphite heating element temperature is reduced.

Therefore, as shown in Figure 4, experimental temperature is lower than simulation temperature in graphite heating component, this phenomenon is more pronounced in the high temperature region.

Overall, the deviation of experimental data and simulation data is within $10 \%$, To modify the physical properties, this conclusion can provide the basis for the numerical simulation of the quartz melting furnace for the 3 -stage continuous heating process.

\section{SIMULATION OF 3-STAGE QUARTZ FUSION FURNACE}

\section{Physical Model}

The physical model of 3-stage quartz fusion furnace is shown in figure 5 .

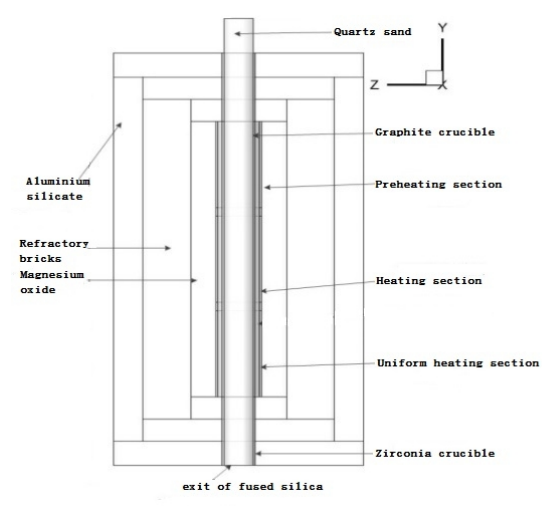

Figure5 Structure diagram

The main parts of this furnace includes aluminum silicate felt, refractory bricks, filling layer of magnesium oxide powder and boron nitride powder, graphite heater elements, graphite crucible and zirconia crucible.

\section{Details of Simulation}

Based on the analysis above, use the concept of equivalent thermal conductivity to fix the thermal conductivity of magnesium oxide layer.

Heat Conduction: $Q=\lambda \cdot \frac{A}{\delta}\left(T_{1}-T_{2}\right)$

Radiation Heat Transfer:

$Q=\xi \sigma A\left(T_{1}^{4}-T_{2}^{4}\right)=\xi \sigma A\left(T_{1}^{2}+T_{2}^{2}\right)\left(T_{1}+T_{2}\right)\left(T_{1}-T_{2}\right)$ Equivalent thermal conductivity: $=\xi \sigma A \cdot 4 \bar{T}^{3}\left(T_{1}-T_{2}\right)$

$$
\lambda_{\text {equivalent }}=4 \xi \sigma \bar{T}^{3} \delta
$$

The total thermal conductivity: 


$$
\lambda_{\text {all }}=\lambda+4 \xi \sigma \bar{T}^{3} \delta
$$

A MRF model is used to simulate the motion of quartz sand. On the outlet surface, the type of boundary layer is a mixture of laminar flow and turbulence flow. The emissivity of the fused quartz on the outlet surface is 0.9 . And the mesh quality is higher than 0.8 .

Because the maximum power of power module in laboratory is $30 \mathrm{~kW}$, heating power of this simulation is set to $30 \mathrm{~kW}$ also. According to the power ratio of stages in the traditional furnace [4], the heating power ratio of this simulation is $12: 10: 3$. The heating power of stages are $30 \mathrm{~kW}$, $25 \mathrm{~kW}$ and $7.5 \mathrm{~kW}$.

\section{Result of simulation}

\section{Production Rate of 3-Stage Quartz Fusion Furnace}

Since the total heating power is certain, assume that all the heat energy generated by the graphite heater is absorbed by system, a maximum mean velocity can be calculated by the following equation.

$P=c_{p} S v \rho \Delta T$

$S$ :Area of the outlet

$\rho$ :Density of quartz on the outlet surface

$v$ :Mean velocity of quartz flowing out of the outlet surface

$c_{p}:$ Mean heat capacity of quartz

$\Delta T:$ Temperature increasing of quartz

The result of simulation shows that the maximum mean velocity is $1 \mathrm{~mm} / \mathrm{s}$. Based on this velocity, 2 lower velocities are simulated to show the temperature distribution in the furnace in different working conditions, so that if the quartz fuses then it leaves the furnace can be understood. The temperature distributions are shown in figure 6 (temperature unit: K).

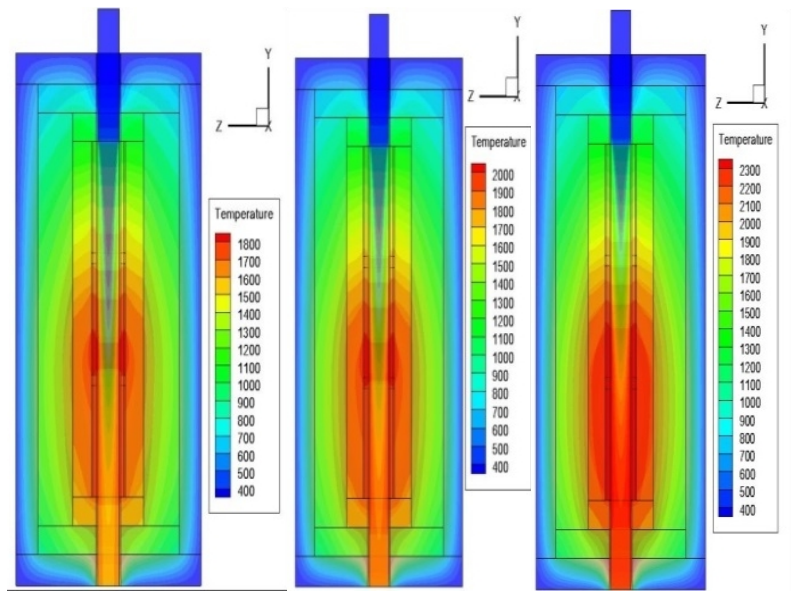

Figure6 simulated results of temperature when speed of quartz is $1 \mathrm{~mm} / \mathrm{s} 、 0.8 \mathrm{~mm} / \mathrm{s}$ and

\section{$0.6 \mathrm{~mm} / \mathrm{s}$}

According to Figure 6, when the mean velocity drops to $0.6 \mathrm{~mm} / \mathrm{s}$, maximum temperature reaches $1800^{\circ} \mathrm{C}$, on which the quartz is certain to fuse. Thus, the following calculation chooses $0.6 \mathrm{~mm} / \mathrm{s}$ of velocity as the outlet boundary condition. 


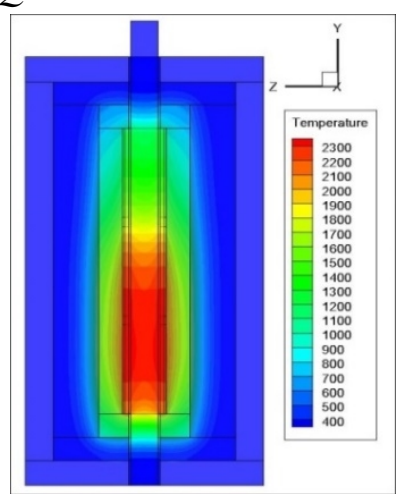

Figure 7 temperature distribution at 3.5 hours

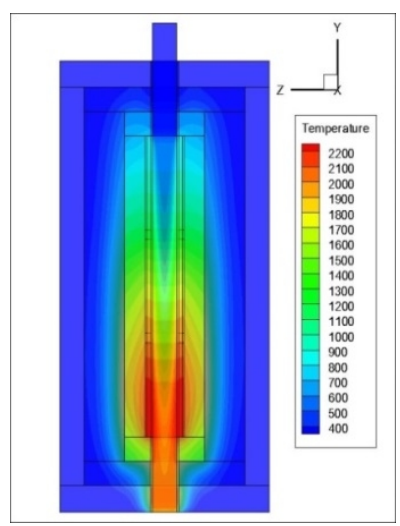

Figure 8 temperature distribution at 5 hours after Continuous quartz importing and exporting

Figure 7 and Figure 8 shows that 3.5 hours after starting to heat, the center's temperature of heating stage reaches $1800^{\circ} \mathrm{C}$ and raw material begins to fuse. 5 hours after the starting, the heating power meet the power needed of stable operation, fused quartz flows out of the furnace continuing.

\section{Temperature Distribution in the Insulation Layer}

The temperature tolerance of magnesium oxide and boron nitride is more than $2400^{\circ} \mathrm{C}$, however, the aluminum oxide bricks can tolerant no more than $1750^{\circ} \mathrm{C}$ and aluminum silicate felt is even lower (about $1000^{\circ} \mathrm{C}$ ). To prevent the furnace from over temperature, the highest temperature of bricks is $1700^{\circ} \mathrm{C}$ and of the felt is $1000^{\circ} \mathrm{C}$.

Due to the heat generation in the whole process, the temperature is going up until the end of simulation time. Thus, final temperatures of the bricks and the felt are parameters of our concern.

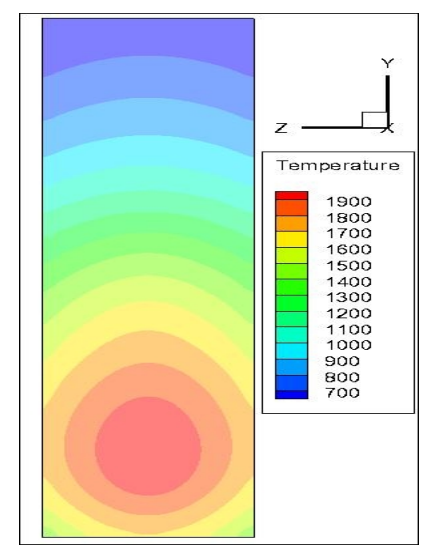

Figure 9 temperature distribution on contacting surface of $\mathrm{MgO}$ and refractory brick 


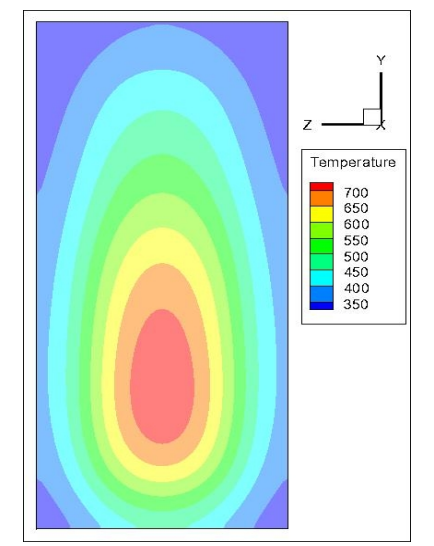

\section{Figure 10 temperature distribution on contacting surface of aluminum silicate layer and refractory brick}

According to Figure 9, final temperature of aluminum oxide bricks is lower than 1680, and according to Figure 10, final temperature of aluminum silicate felt is 730 , which will not exceed the temperature tolerances of material.

\section{Energy Consumption of the Furnace}

Figure 11 shows the energy dissipated to environment in the first 120 hours after starting the furnace. Dissipation rate increase significantly in the first day and then tends to be stable. Fluctuation is due to different heating power (when the price of electricity is high, quartz flow rate is extreme low to save the energy as well as money).

In general, total energy consumption is $0.868 \mathrm{kWh} / \mathrm{kg}$ of this 3 -stage furnace comparing with $1.786 \mathrm{kWh} / \mathrm{kg}$ of the traditional type [5], which means total energy saving ratio is $51 \%$.

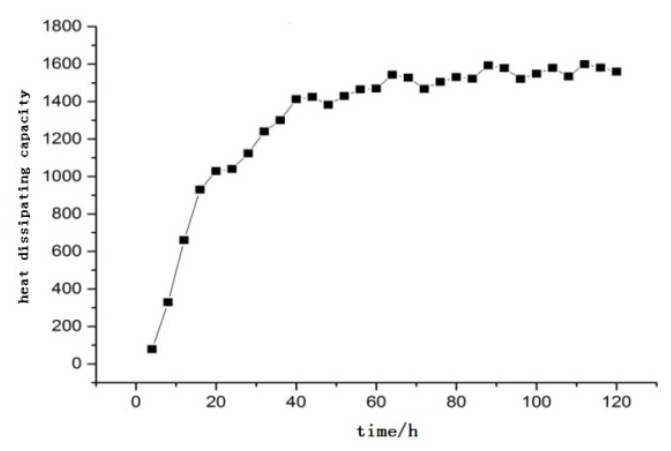

Figure 11 heat dissipation to the environment

\section{CONCLUSION}

(1) In the experiment, magnesium oxide in the insulation layer is powder, however, thermal conductivity used in the simulation is the value of magnesium oxide bricks. When the temperature is low, contact resistance make it harder to transfer heat through this layer. When temperature goes very high, heat transfer through radiation leads to a rapidly temperature increase of the powder, thus, in the late period of experiment, powder's temperature goes higher than the result of simulation.

(2) The model of 3-stage continuous heating furnace is established and simulated, get the following conclusions:The heat insulation layer, heating power and heating mode can be used in 
continuous production of continuous quartz melting furnace, quartz melting furnace insulation layer can play an ideal role in the heat preservation. The total power required for the operation of the furnace is $62.5 \mathrm{~kW}$. Total energy consumption is $0.868 \mathrm{kWh} / \mathrm{kg}$, comparing with the energy consumption of current type $1.786 \mathrm{kWh} / \mathrm{kg}, 51 \%$ energy consumption can be saved.

\section{ACKNOWLEDGMENT}

This work is supported by the Innovation Fund of University-Industry Cooperation (Pro- spective joint research project, Lianyungang, Jiangsu Province, No.BY2013047), the Inno- vation Fund of University-Industry Cooperation (High efficient energy saving project, Lian- yungang, Jiangsu Province, No. CXY1327) and the Foundation of State Key Laboratory of Coal Combustion (No. FSKLCC1109).

\section{REFERENCES}

[1] Helin. Analysis on the industrial competitiveness of silicon in the East China Sea and the Countermeasures of cluster development [D]. Xian: Xi'an University of Technology, 2007. [2] Fasong Shen. Quartz heating groove [D]. Suzhou Casey quartz Electronics Co. Ltd., 2011(04).

[3] Chenlei, Chunli Huang. The energy saving reforming of Lianyungang Faudon quartz continuous melting furnace [D]. Lianyungang Dongwoo Electric Co. Ltd., 2009(04).

[4] Zhanzhong Han, Wangjing, Xiaoping Lan. Fluent examples and application of fluid engineering simulation [M]. Beijing: Beijing Institute of Technology press, 2008

[5] Qiaofang Cai. Heating furnace [M]. Beijing: Metallurgical Industry Press, 2007 